\title{
The test bench of a cascade heatpump installation of a heat power complex for highly effective use secondary and renewables
}

\author{
Vladimir Papin ${ }^{1}$, Roman Bezuglov ${ }^{1, *}$, and Elena Veselovskaya ${ }^{1}$ \\ ${ }^{1}$ Platov South-Russia State Polytechnic University (NPI), Department "Thermal Power Stations and \\ Heat Transfer Engineering", 346400 Novocherkassk, Russia
}

\begin{abstract}
In article the solution of one of the problems facing developers of a heat power complex for highly effective use secondary and renewables reveals. The solved problem is a development of the circuit decisions providing tests of all set of the modes of cascade heatpump installation of a heat power complex, design of the test bench. The developed complex allows to use most effectively together with heatpump installations and thermal accumulators renewables. Also the complex uses also household overflows of energy for the consumer's heat supply, as much as possible reducing consumption of organic fuel.
\end{abstract}

Most available renewable energy sources (RES) and secondary energy resources are characterized by a very uneven intake graphs [1-3]. Consumption graphs have a different form and are more clearly defined. To ensure the graphs of heat and cold consumption, we developed technologies for high-efficiency heat and cold storage. These technologies allow to increase the amount of stored energy up to 4.5 times in comparison with the known solutions, which makes it possible to provide heating and conditioning modes completely at the expense of renewable energy sources. This research was conducted within the framework of the President's scholarship for young scientists 2015-2017 [1]. As a result of the research, a scientific reserve was obtained in the field of highly efficient accumulation of thermal energy. Also, the design documentation for high-efficiency heat and cold accumulators was obtained on the basis of which prototypes of accumulators were manufactured and tested. During researches the main emphasis was put on accumulation of mean seasonal renewable energy. At the same time use of secondary energy resources and overflows of heat fluxes in the consumer was not considered that has the essential potential for energy saving [4-6]. Development of heat power complex for highly effective use secondary and renewable energy resources becomes further development of the idea [7-10]. In this research the problem of complex use of renewable and secondary energy resources taking into account internal overflows of heat energy in the consumer when heating, conditioning, ventilation and hot water supply is solved. It will allow to minimize fuel using in power balance of the building. The energy complex consists of a multi-level compact high-efficiency heat accumulator that provides the accumulation of heat and cold

${ }^{*}$ Corresponding author: romanbezuglov@inbox.ru 
[2]. Tests of multi-level battery do not cause difficulties and do not require bulky systems for their approbation, because each level has fixed temperatures. However, setting up and testing a cascade heat pump system requires larger, more complex and expensive circuits. When creating a heat and power complex, an important task is to confirm its efficient operation and high primary energy coefficient of performance in a cascade heat pump system. For approbation of all cascades the transformation warmth complex it is necessary to have all sources and receivers of the heat energy put in its thermal structure. It is also necessary to provide possibility of utilization of internal energy resources. For carrying out all complex of researches it is necessary to have opportunity upon the demand of the operator to change characteristics of sources and receivers of warmth and cold, and also operating modes of systems of heat consumption and cold. This task difficult is implemented in natural tests on real object, not to mention its cost that within financing of grant would be not real. Therefore by group of developers it was proposed the circuit solution, the providing imitation of work of heat power complex on real object. At the same time there is opportunity at any moment to change scheme parameters for imitation of different operating modes of complex from different renewable and secondary energy resources. The photo of the test bench is shown in the figure 1 .

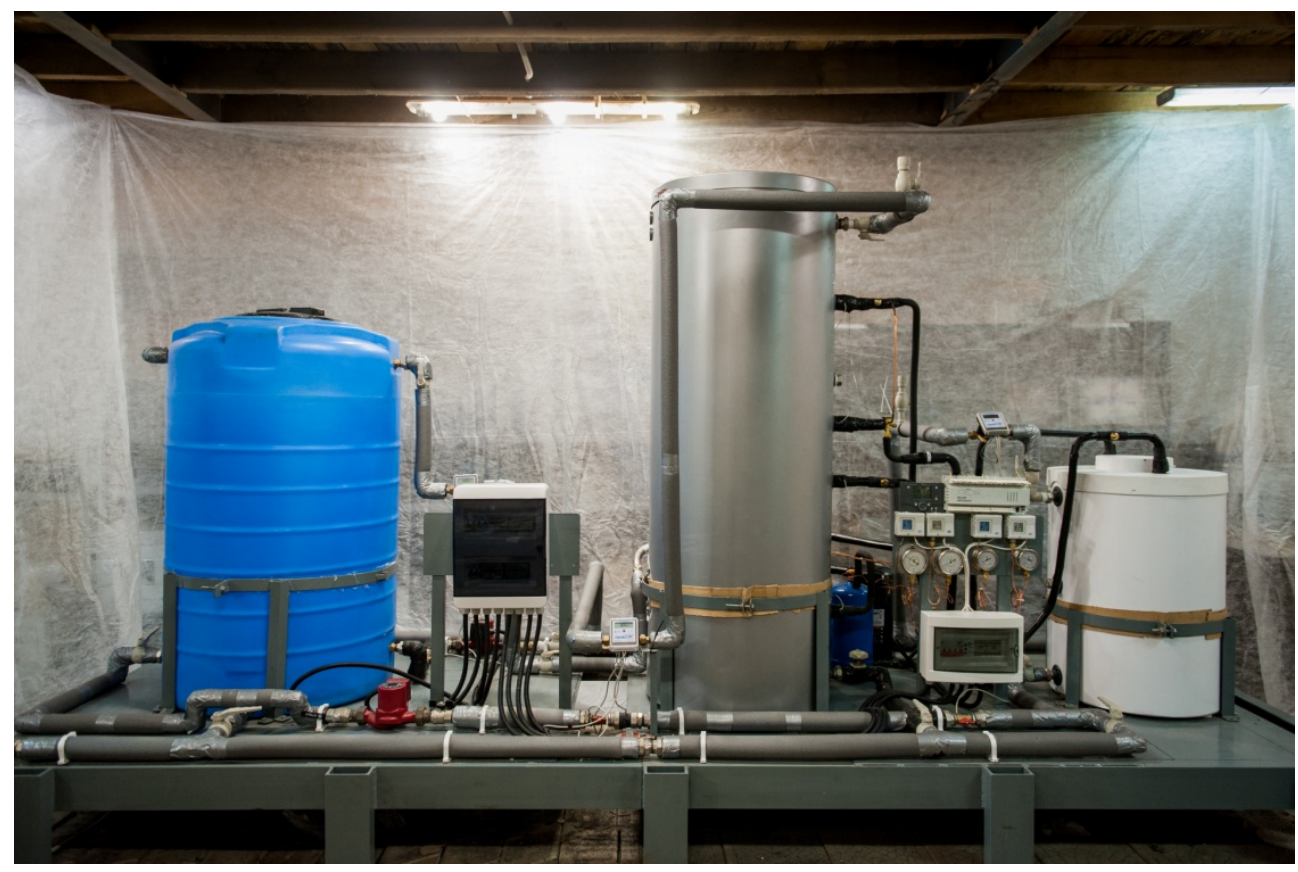

Fig. 1. The test bench of a cascade heatpump installation

The test bench is equipped with two cascades of heat pumps connected consistently. The scheme is shown in the figure 1. In cascades there is opportunity to connect different types of compressors and to fill different brands of freon. On each of cascades sensors for determination of loop variables are installed (temperatures and pressure of freon), counters of the electric power and warmth for determination of power balance of the cascade are connected. The amount of the energy taken from source, amount of the energy transferred to the receiver, amount of the energy going on the compressor drive is defined. Cascade heatpumping installation consists of consecutive and parallel cascades, and the maximum number of consecutive cascades - 2. Parallel cascades can be tested separately, with 
necessary model of the compressor, brand of freon and temperature condition. Consecutive cascades are tested only jointly in number of 2 pieces.

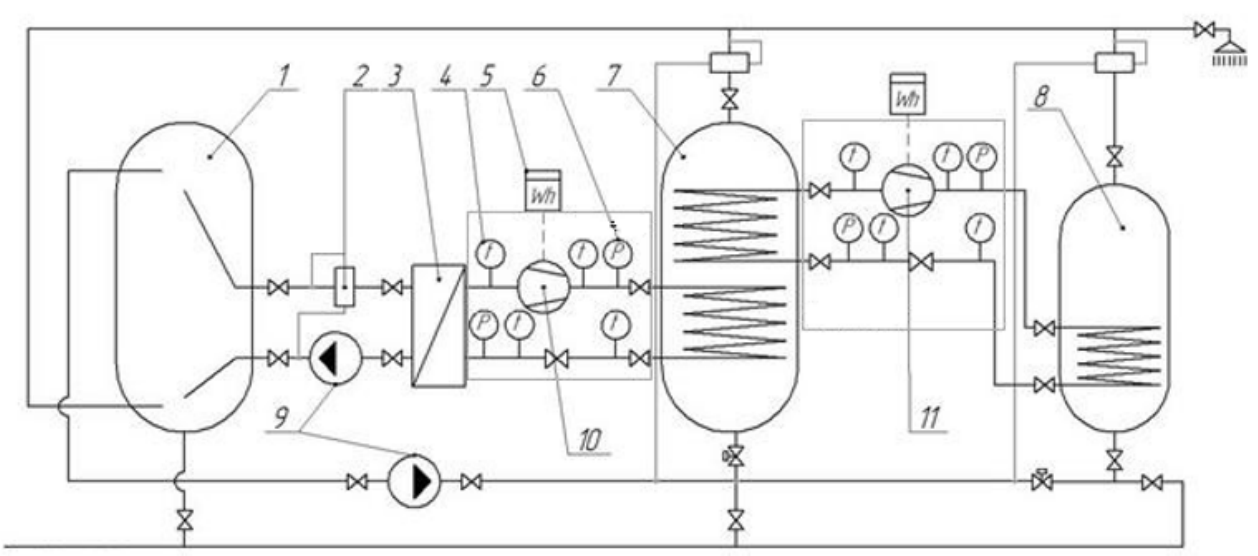

Fig. 2. Scheme the test bench.

Table 1. Specification to the test bench

\begin{tabular}{|c|c|}
\hline № & Name \\
\hline 1 & $\begin{array}{c}\text { Tank } \\
\text { source }\end{array}$ \\
\hline 2 & $\begin{array}{c}\text { Counter of } \\
\text { heat } \\
\text { energy }\end{array}$ \\
\hline 3 & $\begin{array}{c}\text { Plate heat } \\
\text { exchanger }\end{array}$ \\
\hline 4 & $\begin{array}{c}\text { Thermoco } \\
\text { uple }\end{array}$ \\
\hline 6 & $\begin{array}{c}\text { Electric } \\
\text { power } \\
\text { counter }\end{array}$ \\
\hline 7 & $\begin{array}{c}\text { Pressure } \\
\text { relay }\end{array}$ \\
\hline 8 & $\begin{array}{c}\text { Bivalent } \\
\text { boiler }\end{array}$ \\
\hline 10,11 & \begin{tabular}{c} 
Compresso \\
rs \\
Boiler \\
\hline
\end{tabular} \\
\hline 6 & Circulation \\
\hline 5
\end{tabular}

The main distinctive feature of the test stand is its ensuring long-term imitation of source work and the heat receiver at any temperature conditions for testing of the heatpumping cascade, with a thermal power up to $20 \mathrm{~kW}$ with any compressor and coolant. 
Use of the stand excludes need to do different low-potential sources of warmth, such as soil probes, air heat exchangers, solar collectors, etc. Also it excludes need for consumers of warmth, such as the building equipped with radiators, heat-insulated floors, fancoil, etc. But at the same time the stand allows to imitate all above-stated sources and receivers which differ from each other in temperatures at which they work.

This effect is reached due to use of two circulating contours and tanks of sources and receivers. During the operation of the 1st cascade heat energy from tank 1 is pumped over in tank 7. As a result the heat carrier in tank 1 should cool down, and in tank 7 - to heat up. Using the circulating contour and pumps, warmth from heated tank 7 returns to tank 1 . At different speeds of circulation and provisions of the regulating valves it is possible to reach different dynamic temperatures in system of tanks. After establishment of the dynamic mode it is possible to begin tests during which coolant parameters, the warmth received, from source, the warmth given to the receiver and the energy brought to the compressor are measured. Further the coefficient of performance reflecting power efficiency of the cascade in this operating mode is calculated. In the course of operating time, at the expense of warmth supply from network the system will be warmed that is compensated by withdrawal of excess heat energy in system of external cooling.

During the work with two consecutive cascades, heat energy from tank 1 is pumped over by first spool in tank 7 from where by the second cascade it is pumped over in tank 8 at higher potential. Sense of such double cascades in division of temperatures according to levels for heating and hot water supply, at the maximum power efficiency.

Testing is carried out at five different heat carriers:

1.R22; (R134)

2.R406a;(406)

3.R12; (R134)

4.R114; (R404)

5.R502(R507)

Heat carriers are picked up for the heatphysical properties. As these heat carriers are prohibited for use, in tests they will be replaced with the resolved analogs (are provided in brackets).

The system refuels the heat carrier, tests for all contours of the heat pump are carried out. Then the system is drained and filled with the following heat carrier.

Course of tests:

1. Time (30 min.) during which the system comes to nominal rates of indicators is maintained.

2. Each $10 \mathrm{~min}$. meter readings ( 5 times) are taken

3. The analysis of the obtained data on the basis of which average parameters of the cascade heat pump contours are calculated is made.

During tests all data are entered in the corresponding table. The table includes fields as: Freon brand, number of the examinee of contour, temperature, pressure, amount of heat energy, amount of electrical energy, conversion coefficient.

Processing of the obtained data which are compared to rated data is made. During the analysis conclusion about correctness of calculation is formulated and the utilization coefficient of primary energy is defined.

The utilization coefficient of primary energy (COP) is defined by the relation of amount the heat received by the high-potential heat carrier (hot water) of $\mathrm{Q}, \mathrm{kWh}$ to amount of the spent electrical energy $\mathrm{E}, \mathrm{kWh}$ (on coolant compression).

Amount of heat is defined by indications of the counter of heat energy, and the quantity of the spent electric power is defined by indications of the electric counter connected to the compressor of the heat pump.

$$
C O P=Q / E
$$


The amount of heat energy is defined by indications the heat energy counter and the quantity of the spent electric power is defined by indications of the electric counter connected to the heat pump compressor.

The article was prepared with the financial support of the Russian Federation President grant for state support of young Russian scientists - candidates of sciences MK-3537.2018.8

\section{References}

1. V.I. Parshukov, N.N. Efimov, V.V. Papin, R.V. Bezuglov, A.Y. Lagutin, V.V. Kopitsa, Studying possibilities of seasonal cold for application in multifunctional heat supply units, ARPN Journal of Engineering and Applied Sciences v. 13(7), pp. 2623-2631 (2018)

2. N.N. Efimov, V.V. Papin, R.V. Bezuglov, Micro Energy Complex Based on WetSteamTurbine, Procedia Engineering v. 150, pp. 294-299 (2016)

3. Juravleov A.A., Sit M.L., Zubaty A.L., Poponova O.B., Sit B.M., Timchenko D.V. Efficiency of the use of heat pumps on the chp plants. Problems of the Regional Energetics. 2007;2007-1(1):68-71

4. Ghader Yosefi, Sattar Mirzakuchaki, Farshid Raissi, Saeid Afrang, Design and Analysis of a High Force, Low Voltage and High Flow Rate Electro-Thermal Micropump, Micromachines. 2014; 5(4):1323-1341

5. T. A. Ismailov, H. M. Gadjiyev, T. A. Chelushkina, D. A. Chelushkin, Intensification of heat transfer from the ic chip to the heat sink through the use of nanofilm thermoelectric heat pump, Vestnik Dagestanskogo Gosudarstvennogo Tehničeskogo Universiteta: Tehničeskie Nauki. 2014; 32(1):7-15.

6. M Mohammadi Sarduei, H Mortezapour, K Jafari Naeimi, Numerical analysis of using hybrid photovoltaic-thermal solar water heater in Iran, Journal of Agricultural Machinery. 2017;7(1):221-233

7. Yuchao Zeng, Liansheng Tang, Nengyou Wu, Jing Song, Yifei Cao, Orthogonal Test Analysis on Conditions Affecting Electricity Generation Performance of an Enhanced Geothermal System at Yangbajing Geothermal Field, Energies. 2017;10(12):2015.

8. Sit M.L., Andronaty N.R., Sit B.M., Modeling of the heat pump station controlable loop of an intermediate heat-transfer agent, Problems of the Regional Energetics. 2011;2011-2(2(16))

9. Vasilyev Gregory P., Leskov Vitaly A., Mitrofanova Natalia V., Gornov Victor F., Kolesova Marina V., Esaulov Georgiy V., Tabunshchikov Yuriy. A, Technical solution for protection of heat pump evaporators against freezing the moisture condensed, MATEC Web of Conferences. 2016;40.

10. Shilin Aleksandr, Bukreev Viktor, Prohorov Sergey, Pressure pump power control in the primary circuit of the heat exchange system, MATEC Web of Conferences. $2017 ; 91$ 